\title{
Ramucirumab in Indian Patients with Advanced Gastric Cancer-Does Borderline Performance Status and Heavy Burden of Disease in Real World Practice Impact Clinical Benefit?
}

\author{
Anant Ramaswamy ${ }^{1}$ Kripa Bajaj ${ }^{1}$ Vineet Talwar ${ }^{2}$ Kumar Prabhash ${ }^{1} \quad$ Ullas Batra $^{2}$ Boman Dhabhar ${ }^{3}$ \\ Mansi Sharma ${ }^{2} \quad$ Nikhil Ghadyalpatil $^{4}$ Satish $\mathrm{CT}^{5} \quad$ Gautam Goyal $^{6} \quad$ Javvid Muzamil $^{7}$ Amit Bhatt $^{8}$ \\ Parveen Jain ${ }^{2}$ Anantbhushan Ranade ${ }^{8}$ Mangesh Kamath ${ }^{9}$ Jayant Pundlik Gawande ${ }^{10}$ \\ Ravi Thippeswamy ${ }^{11}$ Jimmy Mirani ${ }^{3}$ Neelesh Reddy ${ }^{12}$ Sandip Ganguly ${ }^{13}$ Sourav Kumar Mishra ${ }^{14}$ \\ Irappa Madabhavi ${ }^{15}$ Shashidhara HP ${ }^{5}$ Soumya Surath Panda ${ }^{16}$ Shekar Patil ${ }^{5}$ Prabhat Bhargava ${ }^{1}$ \\ Vikas Ostwal ${ }^{1}$
}

${ }^{1}$ Department of Medical Oncology, TMH, Homi Bhabha National University, Mumbai, Maharashtra, India

2 Department of Oncology, Rajiv Gandhi Cancer Institute and Research Centre, Rohini, Delhi, India

${ }^{3}$ Department of Medical Oncology, Wockhardt Hospitals, Mumbai, Maharashtra, India

${ }^{4}$ Yashoda Cancer Institute, Somajiguda Hyderabad, India

${ }^{5}$ HCG Group of Hospital, Bangalore, Karnataka, India

${ }^{6}$ Department of Oncology, Max Super Speciality Hospital, Mohali, Punjab, India

${ }^{7}$ Department of Medical Oncology, Khyber Superspeciality Institute, Srinagar, Kashmir, J...K, India

${ }^{8}$ Avinash Cancer Clinic, Pune, Maharashtra, India

${ }^{9}$ Gleneagles Global Hospital, Bengaluru, Karnataka, India

${ }^{10}$ Aditya Birla Memorial Hospital, Aditya Birla Hospital Marg, Chinchwad, Pune, Maharashtra, India
Address for correspondence Vikas Ostwal, MD, DM, ECMO, ECMO, Department of Medical Oncology, Tata Memorial Hospital, E. Borges Road, Parel, Homi Bhabha National University, Mumbai 400012, Maharashtra, India (e-mail: dr.vikas.ostwal@gmail.com).

11 Sri Shankara Cancer Hospital Basavangudi, Bangalore, Karnataka, India

12 Columbia Asia Hospital Yeshwantpur, Bangalore, Karnataka, India

13 Department of Medical Oncology, Tata Medical Center, Kolkata, West Bengal, India

${ }^{14}$ Department of Medical Oncology, SUM Hospitals, Bhubaneswar, Odisha, India

${ }^{15}$ Halamma Kerudi Cancer Hospital, Bagalkot, Karnataka, India

16 Department of Medical Oncology, IMS ... SUM Hospital, Bhubaneswar, Odisha, India

\section{South Asian J Cancer 2022;11(1):24-30.}

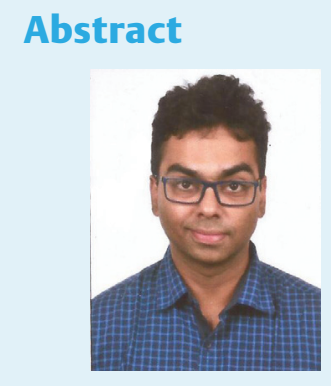

Vikas Ostwal
Background Ramucirumab is considered a standard of care as second-line therapy (CT2) in advanced gastric cancers (AGCs). The aim of this study was to assess practice patterns and outcomes with ramucirumab among Indian patients with AGCs.

Materials and Methods A computerized clinical data entry form was formulated by the coordinating center's (Tata Memorial Hospital) medical oncologists and disseminated through personal contacts at academic conferences as well as via email for anonymized patient data entry. The data was analyzed for clinical characteristics, response rates, and survival outcomes.
DOI https://doi.org/10.1055/s-0041-1728980 ISSN 2278-330X

How to cite this article: Ramaswamy A, Bajaj K, Talwar V, et al. Ramucirumab in Indian Patients with Advanced Gastric CancerDoes Borderline Performance Status and Heavy Burden of Disease in Real World Practice Impact Clinical Benefit? South Asian J Cancer 2022;11(1):24-30. (c) 2021. MedIntel Services Pvt Ltd. All rights reserved.

This is an open access article published by Thieme under the terms of the Creative Commons Attribution-NonDerivative-NonCommercial-License, permitting copying and reproduction so long as the original work is given appropriate credit. Contents may not be used for commercial purposes, or adapted, remixed, transformed or built upon. (https://creativecommons.org/licenses/by-nc-nd/ 4.0/)

Thieme Medical and Scientific Publishers Pvt. Ltd., A-12, 2nd Floor, Sector 2, Noida-201301 UP, India 
Keywords

- Ramucirumab

- ECOG PS $\geq 2$

- advanced gastric cancer

- India
Results A total of 26 physicians contributed data, resulting in 55 patients receiving ramucirumab and being available for analysis. Median age was 53 years (range: $26-78$ ), $69.1 \%$ of patients had greater than two sites of disease, and baseline Eastern Cooperative Oncology Group's performance score (ECOG PS) $\geq 2$ was seen in $61.8 \%$ of patients. Ramucirumab was used as monotherapy in $10.9 \%$ of patients, while the remaining $89.1 \%$ received ramucirumab combined with chemotherapy. Median eventfree survival (EFS) and median overall survival (OS) with ramucirumab were3.53 months (95\% Cl: $2.5-4.57)$ and 5.7 months (95\% Cl: 2.39-9.0), respectively. Common class specific grade adverse events seen with ramucirumab included gastrointestinal (GI) hemorrhage (9.1\% - all grades) and uncontrolled hypertension (Grade 3/4 - 3.6\%). Conclusions Ramucirumab appears to have similar efficacy in Indian AGC patients when compared with real-world data from other countries in terms of median EFS, but OS appears inferior due to more patients having borderline ECOG PS and high metastatic disease burden. GI hemorrhages appear more common than published data, although not unequivocally related to ramucirumab.

\section{What is Already Known?}

Ramucirumab is a recombinant human monoclonal immunoglobulin G1 antibody against human vascular endothelial growth factor (VEGF) receptor 2 (VEGFR2) and is the only anti-VEGF agent approved for use in advanced gastric cancers (AGCs) in the second-line setting.

\section{What is New in this Study?}

A collaborative study of patients with AGC, who were treated by 26 clinicians with ramucirumab across India, which is a reasonably efficacious and safe option, especially with Eastern Cooperative Oncology Group's performance score (ECOG PS) 2 and heavy disease burden.

\section{What are the Future Clinical and Research Implications of the Study Findings?}

We need more studies looking at patients with AGCs with poor performance status and extensive disease burden, as immunotherapy is unlikely to help beyond a small chunk of patients.

\section{Introduction}

Treatment modalities and regimens have gradually improved overall survival (OS) in AGCs over the last decade. Approximately 30 to $65 \%$ of patients progressing on first-line chemotherapy (CT1) in AGC received second-line chemotherapy as per trial data (CT2).$^{1-3}$ Checkpoint inhibitors agents in the form of nivolumab, pembrolizumab and avelumab have further increased treatment options in AGC, although the benefits are modest (pembrolizumab and nivolumab). ${ }^{4-6}$

One of the current standards of care as CT2 in AGC is the combination of paclitaxel plus ramucirumab or ramuciru- mab monotherapy, based on the RAINBOW and REGARD phase III trials. $^{7,8}$ The combination as well as monotherapy showed an OS benefit when compared with paclitaxel monotherapy (9.6 vs. 7.4 months; $p=0.017$ ) and supportive care alone (5.2 vs. 3.8 months; $p=0.047$ ). Besides the OS benefit, ramucirumab appears well-tolerated with a maintained quality of life (QoL) as reported in these studies, when compared with standard chemotherapeutic regimens like irinotecan, docetaxel, paclitaxel and FOLFIRI used as CT2 in AGC. 3,9

While the phase III studies with ramucirumab have established it as standard of care as CT2, the use of this drug in clinical practice may vary compared with respect to prior chemotherapeutic regimens used, companion chemotherapy backbone, and patient factors like PS and tolerance profile. Available real-world data from the RAMoss study and the expanded access program cohort by the Korean Cancer Study Group (KCSG) suggests similar outcomes in nontrial scenarios. ${ }^{10,11}$ The potential prohibitory cost of the drug may also play a factor in limiting its use as opposed to chemotherapeutic agents.

With these factors in mind, we conducted a study with an objective of evaluating how oncologists in India used ramucirumab in their setting in AGC and whether practice patterns and outcomes differed from published data.

\section{Materials and Methods}

\section{Clinical Record Form (CRF)}

A CRF for anonymized patient data entry was created by the medical oncologists (AR and VO) of the coordinating center. The entry form was divided into the following eight domains:

1. Physician details.

2. Demographic patients' details.

3. Baseline disease information.

4. Prior treatment history (brief). 
5. Prior treatment (detailed).

6. Details of ramucirumab-based treatment.

7. Temporal profile of potential class-related adverse events -not reported in manuscript.

8. Practice related questions-not reported in manuscript.

\section{Distribution of CRF}

The CRF was distributed online for anonymized patient data entry. The form was designed on Google forms (Google, Mountain View, CA). Clinicians were identified from a database maintained in the GI medical oncology information system (MOIS) as well as via personal contacts. Individual and group emails with a link to the online CRF were sent to these physicians, and they were requested to reply from April 11, 2018 onward to November 21, 2018.

All responses were recorded electronically and translated into a Google spreadsheet, which was used for analysis. In case of missing data, clinicians were requested to supply the same where available by email responses.

\section{Ethics}

The data collection and handling were conducted as per the ethical guidelines of the declaration of Helsinki. ${ }^{12}$ It was a retrospective analysis of anonymized patient data and consent was not required.

\section{Statistical Analysis}

Data was converted for entry in SPSS software (IBM) version 21 and used for analysis. Descriptive statistics, including median, frequency, and percentage for categorical variables, is used. Event-free survival (EFS) was calculated from the date of starting treatment with ramucirumab to date of permanent cessation of ramucirumab, irrespective of cause of cessation. This was considered as a surrogate for progression-free survival. Overall survival (OS) was calculated from date of starting ramucirumab-based treatment to the date of death or loss to follow-up. Median EFS and OS was calculated using Kaplan-Meier estimates.

\section{Results}

\section{Baseline Demographic and Clinical Characteristics}

A total of 63 patients had their data entered, of which data was found inadequate for analysis for eight entries (-Table 1). The median age of the remaining 55 patients eligible for analysis was 53 years (range: 26-78), 38 patients (69.1\%) were male, $27.3 \%$ had signet ring histology, and $7.3 \%$ were human epidermal growth factor receptor 2 (HER2) positive. Clinically, $40 \%$ of patients had undergone a prior curative resection, $69.1 \%$ had greater than two sites of metastatic disease, and ECOG PS $\geq 2$ was seen in $61.8 \%$ of patients (ECOG PS 2-56.4\%; ECOG PS 3-5.5\%) when starting ramucirumab. Patients had commonly received a triplet docetaxel-based regimen $(38.2 \%)$ or epirubicin-based triplet $(29.1 \%)$ as CT1 before starting on second-line treatment.
Table 1 Baseline demographic and clinical characteristics

\begin{tabular}{|c|c|}
\hline Characteristics & $\begin{array}{l}\text { Number } \\
\text { (percentage } \\
\text { where feasible) }\end{array}$ \\
\hline $\begin{array}{l}\text { Median age (years) } \\
\bullet \geq 65 \\
\cdot<65\end{array}$ & $\begin{array}{l}53(26-78) \\
11(20) \\
44(80)\end{array}$ \\
\hline $\begin{array}{l}\text { Gender } \\
\text { - Male } \\
\text { - Female }\end{array}$ & $\begin{array}{l}38(69.1) \\
17(30.9)\end{array}$ \\
\hline $\begin{array}{l}\text { Pathological details } \\
\text { Degree of differentiation } \\
\text { - Adenocarcinoma NOS } \\
\text { - Well differentiated adenocarcinoma } \\
\text { - Moderately differentiated carcinoma } \\
\text { - Poorly differentiated carcinoma } \\
\text { Signet ring histology } \\
\text { - Yes } \\
\text { - No } \\
\text { - Not available } \\
\text { HER2 status } \\
\text { - Positive } \\
\text { - Negative } \\
\text { - Not tested } \\
\text { Microsatellite status } \\
\text { - Stable } \\
\text { - High } \\
\text { - Not tested }\end{array}$ & $\begin{array}{l}10(18.1) \\
01(1.8) \\
06(10.9 \\
38(69.1) \\
15(27.3) \\
30(54.5) \\
10(18.2) \\
04(7.3) \\
43(78.1) \\
08(14.5) \\
19(34.5) \\
04(7.3) \\
32(58.2)\end{array}$ \\
\hline $\begin{array}{l}\text { Disease status } \\
\text { Prior curative resection } \\
\text { - Yes } \\
\text { - No } \\
\text { Sites of disease } \\
\text { - Primary stomach (including } \\
\quad \text { locoregional recurrences) } \\
\text { - Liver } \\
\text { - Peritoneal/omental } \\
\text { - Pulmonary } \\
\text { - Nonregional nodes } \\
\text { - Osseous } \\
\text { - Soft tissue } \\
\text { - Ovarian deposits (including } \\
\text { Krukenberg's) } \\
\text { Number of metastatic sites } \\
\text { - }>2 \text { sites } \\
\text { - } \geq 2 \text { sites }\end{array}$ & $\begin{array}{l}22(40) \\
33(60) \\
39 \\
28 \\
27 \\
13 \\
31 \\
07 \\
03 \\
03 \\
38(69.1) \\
17(30.9)\end{array}$ \\
\hline $\begin{array}{l}\text { Prior treatment history } \\
\text { Median number of prior lines of therapy } \\
\text { Prior first-line treatment } \\
\text { - Docetaxel-based triplet } \\
\text { - Paclitaxel-based triplet } \\
\text { - Epirubicin-based triplet } \\
\text { - Doublet regimens } \\
\text { - Monotherapy } \\
\text { - Ramucirumab-based first-line therapy }\end{array}$ & $\begin{array}{l}1(0-5) \\
21(38.2) \\
01(1.8) \\
16(29.1) \\
14(25.5) \\
01(1.8) \\
02(3.6)\end{array}$ \\
\hline $\begin{array}{l}\text { ECOG PS } \\
\cdot 0 / 1 \\
\cdot 2 \\
\cdot 3\end{array}$ & $\begin{array}{l}21(38.2) \\
31(56.4) \\
03(5.5)\end{array}$ \\
\hline
\end{tabular}

Abbreviations: ECOG, Eastern Cooperative Oncology Group; epidermal growth factor receptor 2 (HER2); NOS, not otherwise specified; PS, performance status. 
Table 2 Characteristics of therapy with ramucirumab

\begin{tabular}{|c|c|}
\hline Characteristics & $\begin{array}{l}\text { Number } \\
\text { (percentage) }\end{array}$ \\
\hline $\begin{array}{l}\text { Ramucirumab use } \\
\text { Ramucirumab monotherapy/combination } \\
\text { - Monotherapy } \\
\text { - Combination } \\
\text { 1. Paclitaxel } \\
\text { 2. FOLFIRI } \\
\text { 3. FOLFOX } \\
\text { 4. Paclitaxel-carboplatin } \\
\text { 5. Irinotecan } \\
\text { 6. } 5 \text { Fluorouracil } \\
\text { Schedule of ramucirumab used } \\
\text { - Biweekly } \\
\text { - Weekly } \\
\text { - Every } 3 \text { weeks } \\
\text { Dosage of ramucirumab used } \\
\text { - } 8 \mathrm{mg} / \mathrm{kg} \\
\text { - } 6 \mathrm{mg} / \mathrm{kg} \\
\text { - } 4 \mathrm{mg} / \mathrm{kg}\end{array}$ & $\begin{array}{l}06(10.9) \\
49(89.1) \\
40 \\
05 \\
01 \\
01 \\
01 \\
01 \\
48(87.3) \\
06(10.9) \\
01(1.8) \\
45(81.8) \\
05(9.1) \\
05(9.1)\end{array}$ \\
\hline $\begin{array}{l}\text { Treatment-related events with } \\
\text { ramucirumab } \\
\text { Dose reduction/modifications } \\
\text { - Chemotherapy backbone ( } n=49) \\
\text { - Ramucirumab } \\
\text { Class-related grade } 3 / 4 \text { adverse events } \\
\text { - Gastrointestinal bleeding/ } \\
\text { - } \text { Unmorrhage (all grades) } \\
\text { - Thcontrolled hypertension } \\
\text { - Gastrointestinal perforation } \\
\text { Increased requirement of } \\
\text { antihypertensives } \\
\text { - Yes } \\
\text { - No } \\
\text { - No data } \\
\text { Requirement of cardiac evaluation for } \\
\text { suspected cardiac dysfunc-tion } \\
\text { Grade } 3 / 4 \text { adverse events } \\
\text { - Anemia } \\
\text { - Neutropenia } \\
\text { - Febrile neutropenia } \\
\text { - Thrombocytopenia } \\
\text { - Non neutropenic infections } \\
\text { - Diarrhea } \\
\text { - Vomiting }\end{array}$ & $\begin{array}{l}5(10.2) \\
0 \\
05(9.1) \\
02(3.6) \\
0 \\
0 \\
08(14.5) \\
44(80) \\
03(5.5) \\
05(9.1) \\
04(7.3) \\
06(11) \\
03(5.5) \\
03(5.5) \\
03(5.5) \\
02(3.6) \\
02(3.6)\end{array}$ \\
\hline $\begin{array}{l}\text { Response rates } \\
\text { - Partial response } \\
\text { - Stable disease } \\
\text { - Progressive disease } \\
\text { - Not available }\end{array}$ & $\begin{array}{l}11(20) \\
14(25.5) \\
21(38.2) \\
09(16.4)\end{array}$ \\
\hline $\begin{array}{l}\text { Reasons for cessation of ramucirumab } \\
\text { - Progressive disease } \\
\text { - Toxicities } \\
\text { - Cost constraints } \\
\text { - Death while on ramucirumab } \\
\text { (progression/adverse events) } \\
\text { 1. Drug related } \\
\text { 2. Drug unrelated } \\
\text { - Lost to follow-up } \\
\text { - On treatment }\end{array}$ & $\begin{array}{l}24(43.6) \\
06(10.9) \\
03(5.5) \\
05(9.1) \\
01 \\
04 \\
03(5.5) \\
14(25.5)\end{array}$ \\
\hline
\end{tabular}

\section{Characteristics of Therapy with Ramucirumab}

As much as $10.9 \%$ of patients received monotherapy, while the remaining $89.1 \%$ patients received ramucirumab in combination with a chemotherapy backbone (-Table 2). Paclitaxel $(81.6 \% ; n=49)$ was the most common chemotherapy backbone used. As much as $81.8 \%$ of patients were started with a ramucirumab dose of $8 \mathrm{mg} / \mathrm{kg}$.
As much as $10.2 \%$ of patients required dose modifications of the chemotherapy backbone while on ramucirumabbased treatment, while dose reductions of ramucirumab were not required in any patient. Common grade 3 and grade 4 adverse events seen were neutropenia (11\%), anemia (7.3\%), and febrile neutropenia (5.5\%). Class-specific grade $3 / 4$ adverse events relatable to ramucirumab which were noted included uncontrolled hypertension (3.6\%) and gastrointestinal (GI) bleeding/hemorrhage (9.1\%; inclusive of primary tumor bleeds and all grades). No instances of GI perforation or thromboembolism were reported. An increased requirement of antihypertensives was noted in $14.5 \%$ of patients.

\section{Response Rates and Outcomes}

As much as $20 \%$ of patients had a partial response (PR), $25.5 \%$ of patients had stable disease (SD), and $38.2 \%$ of patients had progressive disease (PD) as best response to ramucirumab ( - Table 2). As of cutoff date for analysis, $43.6 \%$ of patients had PD, $10.9 \%$ had ceased treatment due to adverse events, while $25.5 \%$ of patients were still continuing on treatment. Five

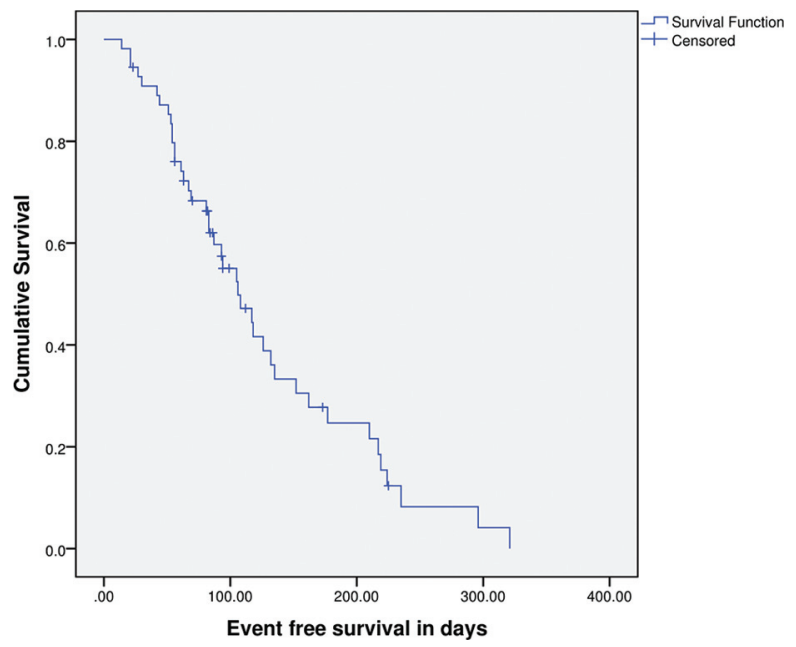

Fig. 1 Event-free survival (EFS).

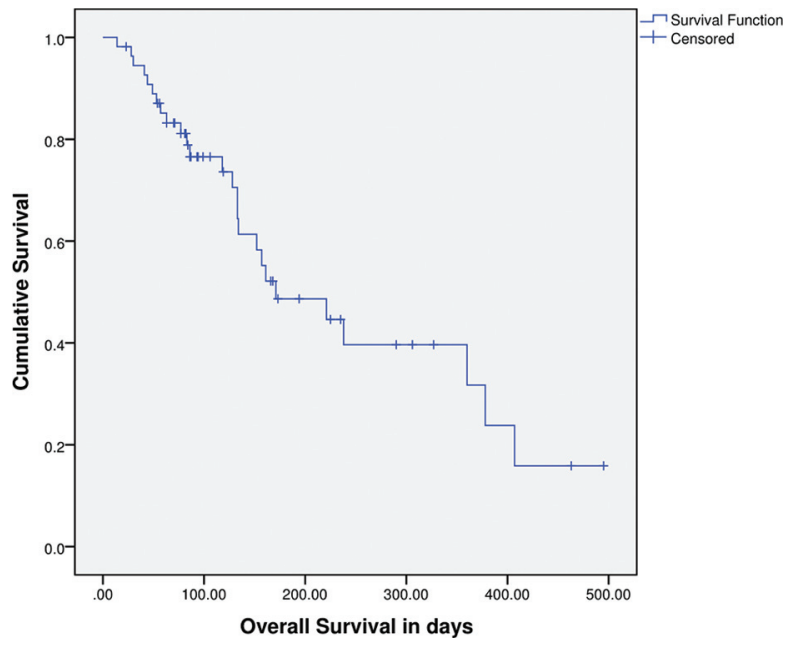

Fig. 2 Overall survival (OS). 
patients died while on treatment, with one patient having died possibly due to ramucirumab-related GI hemorrhage.

With a median follow-up of 4.8 months, median EFS (-Fig. 1) was 3.53 months (95\% CI: 2.5-4.57) and median estimated OS (-Fig. 2) was 5.7 months (95\% CI: 2.39-9.0). Twenty-three patients had died, while 3 patients were lost to follow-up at the time of analysis.

\section{Discussion}

Ramucirumab is a recombinant human monoclonal immunoglobulin G1 antibody against human VEGF receptor 2 (VEGFR2) and is the only anti-VEGF agent approved for use in AGC, albeit in the second-line setting. Besides having a very modest OS benefit when compared with placebo alone in the REGARD study, ramucirumab also showed a trend toward improved global QoL. The RAINBOW study also showed that QoL was maintained on treatment with paclitaxel plus ramucirumab along with an acceptable safety profile. This possibly allows its use in patients with a precarious ECOG PS (ECOG PS $\geq 2$ ), although this has not been examined in a trial setting.

The current study in Indian patients with AGC had the primary aim of ensuring collaboration between Indian medical oncologists in evaluating the clinical presentation and outcomes in patients receiving ramucirumab. The cohort of
55 patient data examined in this study showed a few points of interest requiring elucidation. Most patients received paclitaxel as the chemotherapy backbone with ramucirumab, but a few patients also received other accompanying regimens (10.9\%). These percentages will likely rise in the near future, considering the increasing use of the docetaxelbased docetaxel, oxaliplatin, fluorouracil, and leucovorin (FLOT) regimens in the perioperative setting and a possible reluctance in using a potentially cross-resistant agent, i.e., paclitaxel on recurrence. ${ }^{13}$ FOLFIRI or irinotecan are possible options in such a scenario and their feasibility in combination with ramucirumab has already been shown in colorectal cancers. $^{1,4}$

A significant proportion of patients had signet ring histology $(27.3 \%)$, which is equivocally considered as a poor prognostic marker in AGC. ${ }^{15,16}$ A majority of patients had ECOG $P S \geq 2$, which would be expected in patients who have progressed post-CT1 in AGC. ECOG PS 2 has also been shown to be a strong predictor of inferior outcomes in AGC from large well-conducted retrospective studies. ${ }^{17,18}$ However, data on the efficacy of ramucirumab in patients with inferior ECOG PS is lacking, as such patients are usually systematically excluded from clinical trials. Again, the current study cohort had patients with a high metastatic disease burden ( $69.1 \%$ of patients had $>2$ sites of metastatic disease). When a cohort with such unfavorable characteristics (high

Table 3 Comparison of real-world studies evaluating ramucirumab in advanced gastric cancer

\begin{tabular}{|c|c|c|c|}
\hline Characteristic & EAP-KCSG & RAMoss & Current study \\
\hline Number of patients & 265 & 167 & 55 \\
\hline Region & South Korea & Italy & India \\
\hline $\begin{array}{l}\text { ECOG PS } \\
\cdot 0 / 1 \\
\cdot \geq 2\end{array}$ & $\begin{array}{l}94.6 \\
5.4\end{array}$ & $\begin{array}{l}88.7 \\
11.3\end{array}$ & $\begin{array}{l}38.2 \\
61.2\end{array}$ \\
\hline $\begin{array}{l}\text { Number of metastatic sites } \\
\cdot 0-2 \\
\cdot \geq 3\end{array}$ & $\begin{array}{l}73 \\
27\end{array}$ & $\begin{array}{l}- \\
-\end{array}$ & $\begin{array}{l}30.9 \\
69.1\end{array}$ \\
\hline $\begin{array}{l}\text { Ramucirumab use } \\
\text { - Monotherapy } \\
\text { - Combined with chemotherapy }\end{array}$ & $\begin{array}{l}13.7 \\
86.4\end{array}$ & $\begin{array}{l}10.2 \\
89.8\end{array}$ & $\begin{array}{l}10.9 \\
89.1\end{array}$ \\
\hline $\begin{array}{l}\text { Response rates (\%) } \\
\text { - Complete response } \\
\text { - Partial response } \\
\text { - Stable disease } \\
\text { - Progressive disease } \\
\text { - Clinical benefit rate } \\
\text { - NA }\end{array}$ & $\begin{array}{l}0.4 \\
14.7 \\
47.2 \\
30.2 \\
61.9 \\
7.5\end{array}$ & $\begin{array}{l}1.3 \\
18.9 \\
39.2 \\
40.6 \\
58.1 \\
-\end{array}$ & $\begin{array}{l}0 \\
20 \\
25.5 \\
38.2 \\
45.5 \\
16.4\end{array}$ \\
\hline $\begin{array}{l}\text { Class specific grade } 3 / 4 \text { toxicities (\%) } \\
\text { - Gl hemorrhage (all grades) } \\
\text { - Gl perforation } \\
\text { - Thromboembolic events } \\
\text { - Uncontrolled hypertension }\end{array}$ & $\begin{array}{l}1.3 \\
2.3 \\
0.8 \\
1.1\end{array}$ & $\begin{array}{l}7.7 \text { (bleeding) } \\
0 \\
0 \\
0.6\end{array}$ & $\begin{array}{l}9.1 \\
0 \\
0 \\
3.6\end{array}$ \\
\hline Median PFS (months) & $\begin{array}{l}1.8 \text { (mono) } \\
3.8 \text { (combination) }\end{array}$ & $\begin{array}{l}2.7 \text { (mono) } \\
4.4 \text { (combination) }\end{array}$ & 3.53 (EFS) \\
\hline Median OS (months) & $\begin{array}{l}6.4 \text { (mono) } \\
8.6 \text { (combination) }\end{array}$ & $\begin{array}{l}4.8 \text { (mono) } \\
8.6 \text { (combination) }\end{array}$ & 5.7 \\
\hline
\end{tabular}

Abbreviations: EAP-KCSG, expanded access program in Korean Cancer Study Group ECOG, Eastern Cooperative Oncology Group; EFS, event-free survival; GI, gastrointestinal; NA, not available; OS, overall survival; PS, performance status; PFS, progression-free survival. 
proportion of signet ring histology, predominantly ECOG PS $\geq 2$, high metastatic burden) is evaluated, outcomes would be expected to be inferior to published data. Thus, as expected, the median OS in the current study is 5.7 months, which is less than the survival seen in the RAINBOW trial (9.6 months). A more relevant comparison with the real-world RAMoss study and the data from the expanded access program in Korea (EAP-KCSG) is shown in - Table 3. As can be evinced, the patients in both these studies had baseline characteristics, which approximated patients being considered for trials (predominantly ECOG PS 0/1, less metastatic burden of disease) and expectedly had a similar OS (RAMoss -8.6 months for combination arm; EAP-KCSG-8.6 months for combination arm). However, the PFS across the studies is similar (RAMoss-4.4 months for combination arm; EAPKCSG-3.8 months for combination arm; current study [EFS]-3.53 months), suggesting that ramucirumab is reasonably efficacious even in patients with ECOG PS 2 and heavy metastatic burden of disease.

Patients profiled in the study appeared to have tolerated ramucirumab well with no new safety signals seen. There were no instances of GI perforation or thromboembolic events in the study. GI hemorrhages appeared to be significantly more common $(9.1 \%)$ but was reported by physicians as being tumor-related bleed, with only one instance of the bleed being attributable to ramucirumab causing death. There was a slightly increased incidence of hypertension, and requirement of increased antihypertensives was seen (14.5\%), but grade $3 / 4$ hypertension was only marginally high (3.6\%).

The current collaborative study comprises a cohort of patients with AGC who have been treated by 26 clinicians with ramucirumab across India and is an accurate representation of practice patterns employed by them. The number of patients accrued in the study is also indicative of the small numbers of patients who are potentially feasible for this drug, based on logistic and financial constraints in India, although a further discussion on this aspect is beyond the scope of this study. The strengths of the current study lie in showing that ramucirumab is a reasonably efficacious and safe option as second-line therapy in Indian patients with AGC, especially with ECOG PS 2 and heavy disease burden. It also provides limited evidence that patients with poor ECOG PS (PS 2) can be treated with ramucirumab-based therapy, although outcomes are expectedly inferior. However, multiple caveats exist when reporting outcomes in such small data cohorts. Physicians entered data online and hence there may be bias in reporting and recall of patient-related details. We are unable to evaluate any prognostic or predictive factors with regard to outcomes as the small numbers preclude any such relevant statistical analysis. Decisions on whether ramucirumab should be used in patients with poor PS still remains unanswered, although answers are unlikely to be forthcoming, given the nature of patient selection in clinical trials.

In conclusion, ramucirumab appears to have similar efficacy in Indian gastric cancer patients when compared with real-world data from other countries in terms of median PFS, but OS appears to be lower due to the treatment of more patients with ECOG PS $\geq 2$ and higher metastatic burden of disease. GI hemorrhages appear more common than published data, although it is possibly related to tumor hemorrhage than ramucirumab.

Funding

No funding received for study.

\section{Conflict of Interest}

The authors declare that they have no conflict of interest.

Acknowledgments

We would like to thank Ms. Priyanka P Kadvekar in helping us format the questionnaire online into Google forms.

\section{References}

1 Koizumi W, Narahara H, Hara T, et al. S-1 plus cisplatin versus S-1 alone for first-line treatment of advanced gastric cancer (SPIRITS trial): a phase III trial. Lancet Oncol 2008;9(03):215-221

2 Guimbaud R, Louvet C, Ries P, et al. Prospective, randomized, multicenter, phase III study of fluorouracil, leucovorin, and irinotecan versus epirubicin, cisplatin, and capecitabine in advanced gastric adenocarcinoma: a French intergroup (Fédération Francophone de Cancérologie Digestive, Fédération Nationale des Centres de Lutte Contre le Cancer, and Groupe Coopérateur Multidisciplinaire en Oncologie) study. J Clin Oncol 2014;32 (31):3520-3526

3 Takahari D. Second-line chemotherapy for patients with advanced gastric cancer. Gastric Cancer 2017;20(03):395-406

4 Muro K, Chung HC, Shankaran V, et al. Pembrolizumab for patients with PD-L1-positive advanced gastric cancer (KEYNOTE-012): a multicentre, open-label, phase 1b trial. Lancet Oncol 2016;17(06):717-726

5 Shitara K, Özgüroğlu M, Bang Y-J, et al.KEYNOTE-061 investigators. Pembrolizumab versus paclitaxel for previously treated, advanced gastric or gastro-oesophageal junction cancer (KEYNOTE-061): a randomised, open-label, controlled, phase 3 trial. Lancet 2018;392(10142)123-133

6 Kang Y-K, Boku N, Satoh T, et al. Nivolumab in patients with advanced gastric or gastro-oesophageal junction cancer refractory to, or intolerant of, at least two previous chemotherapy regimens (ONO-4538-12, ATTRACTION-2): a randomised, double-blind, placebo-controlled, phase 3 trial. Lancet 2017;390 (10111)2461-2471

7 Wilke H, Muro K, Van Cutsem E, et al.RAINBOW Study Group. Ramucirumab plus paclitaxel versus placebo plus paclitaxel in patients with previously treated advanced gastric or gastrooesophageal junction adenocarcinoma (RAINBOW): a doubleblind, randomised phase 3 trial. Lancet Oncol 2014;15(11): 1224-1235

8 Zhu AX, Park JO, Ryoo B-Y, et al.REACH Trial Investigators. Ramucirumab versus placebo as second-line treatment in patients with advanced hepatocellular carcinoma following first-line therapy with sorafenib (REACH): a randomised, double-blind, multicentre, phase 3 trial. Lancet Oncol 2015;16(07): 859-870

9 Ramaswamy A, Ostwal V, Gupta K, et al. Modified 5-fluorouracil/leucovorin/irinotecan as a feasible and efficacious secondline chemotherapeutic regimen in advanced gastric cancers. South Asian J Cancer 2018;7(04):219-222

10 Di Bartolomeo M, Niger M, Tirino G, et al. Ramucirumab as second-line therapy in metastatic gastric cancer: real-world data from the RAMoss study. Target Oncol 2018;13(02):227-234 
11 Jung M, Ryu M-H, Oh DY, et al. Efficacy and tolerability of ramucirumab monotherapy or in combination with paclitaxel in gastric cancer patients from the Expanded Access Program Cohort by the Korean Cancer Study Group (KCSG). Gastric Cancer 2018;21(05):819-830

12 WMA - The World Medical Association-WMA Declaration of Helsinki - Ethical Principles for Medical Research Involving Human Subjects [Internet]. [cited 2018 Jan 25]. Last accessed March 24, 2021 at: https://www.wma.net/policies-post/wmadeclaration-of-helsinki-ethical-principles-for-medical-researchinvolving-human-subjects/

13 Al-Batran S-E, Homann N, Schmalenberg H, et al. Perioperative chemotherapy with docetaxel, oxaliplatin, and fluorouracil/ leucovorin (FLOT) versus epirubicin, cisplatin, and fluorouracil or capecitabine (ECF/ECX) for resectable gastric or gastroesophageal junction (GEJ) adenocarcinoma (FLOT4-AIO): A multicenter, randomized phase 3 trial. J Clin Oncol 2017;35(15_suppl)4004-4004

14 Tabernero J, Yoshino T, Cohn AL, et al. RAISE Study Investigators. Ramucirumab versus placebo in combination with second-line
FOLFIRI in patients with metastatic colorectal carcinoma that progressed during or after first-line therapy with bevacizumab, oxaliplatin, and a fluoropyrimidine (RAISE): a randomised, double-blind, multicentre, phase 3 study. Lancet Oncol 2015;16(05): 499-508

15 Taghavi S, Jayarajan SN, Davey A, Willis AI. Prognostic significance of signet ring gastric cancer. J Clin Oncol 2012;30(28): 3493-3498

16 Signet-ring cell carcinoma of the stomach: Impact on prognosis and specific therapeutic challenge [Internet]. [cited 2019 Jan 22]. Available at: https://www.ncbi.nlm.nih.gov/pmc/articles/PMC4616218/ . Last accessed March 24, 2021

17 Shitara K, Muro K, Matsuo K, et al. Chemotherapy for patients with advanced gastric cancer with performance status 2. Gastrointest Cancer Res 2009;3(06):220-224

18 Fanotto V, Cordio S, Pasquini G, et al. Prognostic factors in 868 advanced gastric cancer patients treated with second-line chemotherapy in the real world. Gastric Cancer 2017;20(05): 825-833 